\title{
Microzooplankton grazing on phytoplankton in the Rhode River, Maryland: nonlinear feeding kinetics
}

\author{
Charles L. Gallegos \\ Smithsonian Environmental Research Center, PO Box 28, Edgewater, Maryland 21037, USA
}

\begin{abstract}
The dilution technique estimates microzooplankton grazing on phytoplankton by reducing encounter rates between the microzooplankton predators and their phytoplankton prey. The technique was extended to the case in which grazing is a nonlinear function of phytoplankton concentration. By allowing microzooplankton clearance rates to vary between, but not within, dilution fractions, and assuming microzooplankton density remains constant, it was shown that the grazing impact on apparent phytoplankton growth rate bears a simple relationship to the functional response of the microzooplankton. Experiments in the Rhode River, Maryland (USA) demonstrated saturated feeding kinetics. Half-saturation chlorophyll concentrations occurred within a relatively small fraction $(0.1$ to 0.2) of initial concentrations, despite a 4 -fold range in the latter, suggesting tight coupling between microzooplankton communities and their phytoplankton prey. Simulations with time-dependent equations coupling phytoplankton and microzooplankton growth laws indicated that inferences about the shape of the microzooplankton functional response from measurements of phytoplankton apparent growth rate are insensitive to change in microzooplankton density and to changes in clearance rates along the functional response. However, estimates of specific grazing coefficient, $g$, are very sensitive to these changes. Equations were solved for the case when the specific ingestion rate of the microzooplankton is food-saturated. The solution allows for proper estimation of $g$ in eutrophic systems whenever microzooplankton growth rate is observed.
\end{abstract}

\section{INTRODUCTION}

Grazing by microzooplankton is believed to play at least 3 important roles in planktonic foodwebs. Grazing may reguiate the population levels of bacteria and nanophytoplankton (Verity 1986, McManus \& Fuhrman 1988); microzooplankton grazing appears to dominate all other sources of nutrient regeneration in most environments studied (Harrison 1980); dissolved organic carbon excreted by phytoplankton and scavaged by bacteria may be transferred to larger metazoan grazers via microzooplankton grazing, although the significance of this link is controversial (Ducklow et al. 1986, Sherr et al. 1987a).

Given the significance of microzooplankton grazing, it is important that the methods used to measure it be given close scrutiny. The available techniques for measuring microzooplankton grazing have recently been reviewed by McManus \& Fuhrman (1988) and Gifford (1988). Each method has certain advantages and disadvantages. The dilution technique, introduced by Landry \& Hassett (1982), has the advantage that the technique requires relatively little manipulation of the community, and yields estimates of both the specific growth rate of the phytoplankton and specific grazing rate of the microzooplankton. With this technique the grazing rate is estimated by determining the apparent growth rate of the phytoplankton in a series of containers in which sampled water is diluted with filtered water from the same location. The dilutions reduce the probability of encounter between microzooplankton (i.e. the predator) and phytoplankton (the prey). The specific growth rate of the phytoplankton is given as the apparent growth rate extrapolated to $100 \%$ dilution (i.e. the growth rate in the complete absence of grazers); the microzooplankton grazing rate is calculated from the slope of a regression of apparent growth rate against the fraction of unfiltered water (see below, 'Theory').

A possible disadvantage of the dilution technique is that 4 critical assumptions must be satisfied which may be difficult to verify in practice: (1) The growth rate of 
the phytoplankton must not be altered by dilution per se (i.e. growth must not be density-dependent); (2) growth of the phytoplankton must not be limited by available or regenerated nutrients; (3) phytoplankton must be growing exponentially with time, and (4) consumption rates of the microzooplankton must be linear with respect to phytoplankton concentration. Consequences of violating these assumptions have been discussed (Landry \& Hassett 1982, Ducklow \& Hill 1985, Tremaine \& Mills 1987, Gifford 1988).

Here I consider the consequences of nonlinear feeding kinetics by the microzooplankton grazers (Assumption 4). I show that for well-behaved feeding response functions, nonlinearity should lead to predictable and interpretable effects on the plot of apparent growth rate against the fraction of unfiltered water. The modifications to account for nonlinear feeding kinetics have implications for the experimental protocol, particularly for determining the most informative dilutions to perform. Application of the modified technique to plankton communities in the Rhode River, Maryland (USA) showed signs of saturated feeding kinetics, and gave growth and grazing estimates that differ from linear estimates.

\section{THEORY}

As originally proposed (Landry \& Hassett 1982) the dilution technique assumes that the phytoplankton are growing exponentially and are simultaneously being grazed

$$
\mathrm{P}_{t}=\mathrm{P}_{0} \exp [(k-g) t]
$$

which can be solved for the net growth rate, $I_{\mathrm{n}}$

$$
r_{\mathrm{n}} \equiv k-g=(1 / t) \ln \left[\mathrm{P}_{1}(t) / \mathrm{P}_{1}(0)\right]
$$

where $\mathrm{P}=$ phytoplankton biomass or population numbers; $k=$ phytoplankton exponential growth rate $\left(\mathrm{d}^{-1}\right)$; $g=$ specific grazing rate of the microzooplankton $\left(\mathrm{d}^{-1}\right)$; $t=$ time $(\mathrm{d})$; and the subscript 1 denotes an undiluted incubation (fraction of unfiltered seawater $=1$ ). Given the assumptions stated in the 'Introduction', the grazing impact may be reduced without altering growth rate by diluting the sample with filtered water; grazing is reduced by a factor $X$, where $X(0<X \leqq 1)$ is the fraction of unfiltered water in the dilution. Solution of Eq. (1) gives a linear relationship between apparent growth rate in the diluted sample, $r_{X}$, and $X$

$$
r_{\mathrm{X}} \equiv(1 / t) \ln \left[\mathrm{P}_{\mathrm{t}} / \mathrm{P}_{\mathrm{O}}\right)=k-\mathrm{X} g
$$

The phytoplankton growth rate should be the $y$-intercept and grazing rate -1 times the slope of a regression of $r_{X}$ against $X$. For detection of a linear relationship some investigators have used dilutions spaced fairly evenly along the $X$ axis (Landry \& Hassett 1982, Burkill et al. 1987, Paranjape 1987. Gifford 1988). Others have used incubations at $X=1$ and at one other value of $X$ to estimate $k$ and $g$ by simultaneous solution of Eqs. (1b) and (2) (Landry et al. 1984, Ducklow \& Hill 1985). I will refer to these 2 solution techniques as the regression and 2-point methods, respectively.

The success of the linear solutions depends on the assumption that the community grazing impact is reduced in direct proportion to $\mathrm{X}$. This is equivalent to assuming that the per capita clearance rate by the microzooplankton grazers (volume filtered per grazer per time) remains constant at all dilutions. To relax this assumption we may assume that the community ingestion rate varies discretely, but nonlinearly, with dilution fraction, $\mathrm{X}$

$$
\mathrm{I}_{\mathrm{X}}=f_{\mathrm{X}}\left(\mathrm{P}_{\mathrm{X}}\right)
$$

where $\mathrm{I}_{\mathrm{X}}=$ community ingestion rate [(mass phytoplankton consumed) grazer $\left.{ }^{-1} \mathrm{~d}^{-1}\right]_{i} P_{X}=$ phytoplankton concentration initially present in dilution fraction $X_{\text {; }}$ and $f_{\mathrm{X}}\left(\mathrm{P}_{\mathrm{X}}\right)$, the discrete community functional response curve, is an unspecified, possibly nonlinear function of $\mathrm{P}_{\mathrm{X}}$. The community clearance rate at dilution $\mathrm{X}_{1} \mathrm{C}_{\mathrm{X}}(\mathrm{ml}$ grazer ${ }^{-1} \mathrm{~d}^{-1}$ ), is then

$$
\mathrm{C}_{\mathrm{X}}=\mathrm{I}_{\mathrm{X}} / \mathrm{P}_{\mathrm{X}}
$$

The community grazing coefficient in an undiluted $(X=1)$ sample is the product of the clearance rate and the concentration of grazers, $\mathrm{Z}$ (organisms $\mathrm{ml}^{-1}$ ),

$$
g=\mathrm{C}_{1} \mathrm{Z}=\mathrm{Z} \cdot \mathrm{I}_{1} / \mathrm{P}_{1}=\mathrm{Z} \cdot f_{1}\left(\mathrm{P}_{1}\right) / \mathrm{P}_{1}
$$

To proceed we must make 2 additional assumptions. First, we require that microzooplankton density remain constant during the incubation. Secondly, we must assume that alteration of clearance rates by the microzooplankton community is a response to the initial dilution treatment, but that clearance rates otherwise remain temporally constant within all dilutions; that is, $f_{X}\left(P_{X}\right)$ is not a continuously varying function of $P$. These are severe restrictions, and without them, the following development has no general mathematical validity. Consequences of relaxing these additional assumptions will be explored in the 'Discussion' using a more general, time-dependent model of community dynamics. It is useful to proceed, because, as will be shown, the derivations suggest a transformation of the data that is useful for detecting the presence of nonlinear feeding kinetics even when the assumptions are not met.

Making these assumptions and substituting Eq. (5) into (1b) gives $r_{\mathrm{n}}$ as

$$
r_{\mathrm{n}}=k-\mathrm{Z} f_{1}\left(\mathrm{P}_{1}\right) / \mathrm{P}_{1}
$$

Dilution of a sample with filtered water reduces con- 
centrations of both grazers and phytoplankton by a factor $X$, so that in the diluted samples

$$
\begin{aligned}
r_{\mathrm{X}}= & k-\left(\begin{array}{ll}
\mathrm{X} & \mathrm{Z}
\end{array}\right) f_{\mathrm{X}}\left(\begin{array}{ll}
\mathrm{X} & \mathrm{P}_{1}
\end{array}\right) /\left(\mathrm{X} \cdot \mathrm{P}_{1}\right) \\
& =k-\mathrm{Z} \quad f_{\mathrm{X}}\left(\begin{array}{ll}
\mathrm{X} & \mathrm{P}_{1}
\end{array}\right) / \mathrm{P}_{1}
\end{aligned}
$$

Substituting for $Z / P_{1}$ from Eq. (5) and letting $P_{X}=X \cdot P_{1}$ gives

$$
r_{\mathrm{X}}=k-\left[f_{\mathrm{X}}\left(\mathrm{P}_{\mathrm{X}}\right) / f_{1}\left(\mathrm{P}_{1}\right)\right] \cdot g
$$

The fraction $f_{\mathrm{X}}\left(\mathrm{P}_{\mathrm{X}}\right) / f_{1}\left(\mathrm{P}_{1}\right)$ in Eq. $(7 \mathrm{c})$ is just the discrete functional response curve scaled to the ingestion rate at the ambient, undiluted phytoplankton concentration. Since $X$ is the fraction by which initial phytoplankton density is reduced, we may refer to a plot of $f_{X}\left(\mathrm{P}_{\mathrm{X}}\right) / f_{1}\left(\mathrm{P}_{1}\right)$ vs $\mathrm{X}$ as the normalized functional response curve. When $f_{\mathrm{X}}\left(\mathrm{P}_{\mathrm{X}}\right) / f_{1}\left(\mathrm{P}_{1}\right)=\mathrm{X}$ then $f_{\mathrm{X}}\left(\mathrm{P}_{\mathrm{X}}\right)$ is by definition linear and the technique as originally proposed is appropriate. For the more general case we can deduce the expected behavior of the curve of $r_{\mathrm{X}}$ vs $\mathrm{X}$ by examining some proposed functional response curves. Three types of functional response curves are generally recognized in predator-prey dynamics (Holling 1959, cited in Real

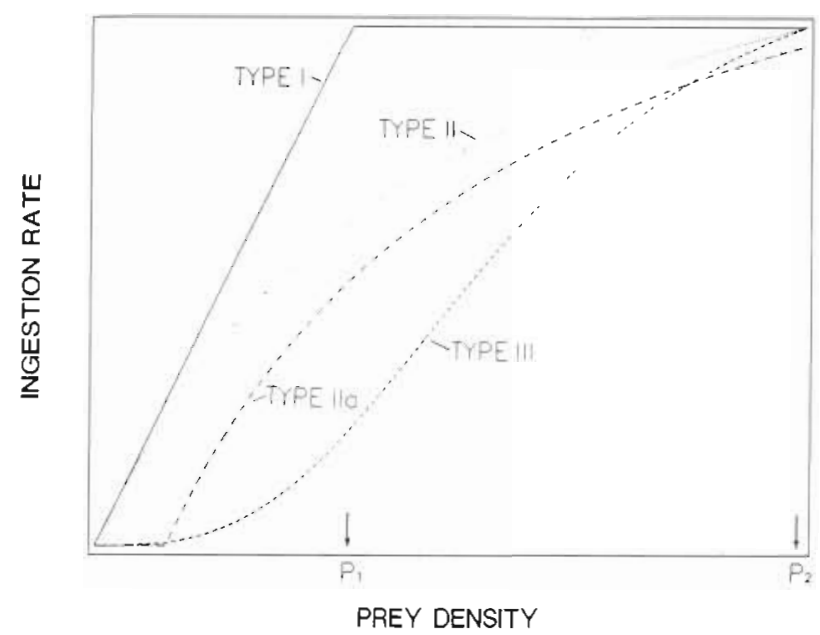

Fig. 1. Generalized functional response curves recognized in predator-prey dynamics. Points $P_{1}$ and $P_{2}$ were used as initial prey densities for generating curves in Fig. 2 (see text)

1977; see also Steele 1974): Type I is a linear rise in feeding rate to a saturation level; Type II is a decelerating rise to an asymptotic maximum, and Type III is sigmoidal (Fig. 1). I have added a modified Type II (Type Ila) to admit the possibility that microzooplankton feeding may cease below a threshold food concentration (Steele 1974; see also Gifford 1988, Rublee \& Gallegos 1989).

The curves of $I_{X}$ vs $\mathrm{X}$ generated by the 4 types of functional responses are given for 2 different concen-

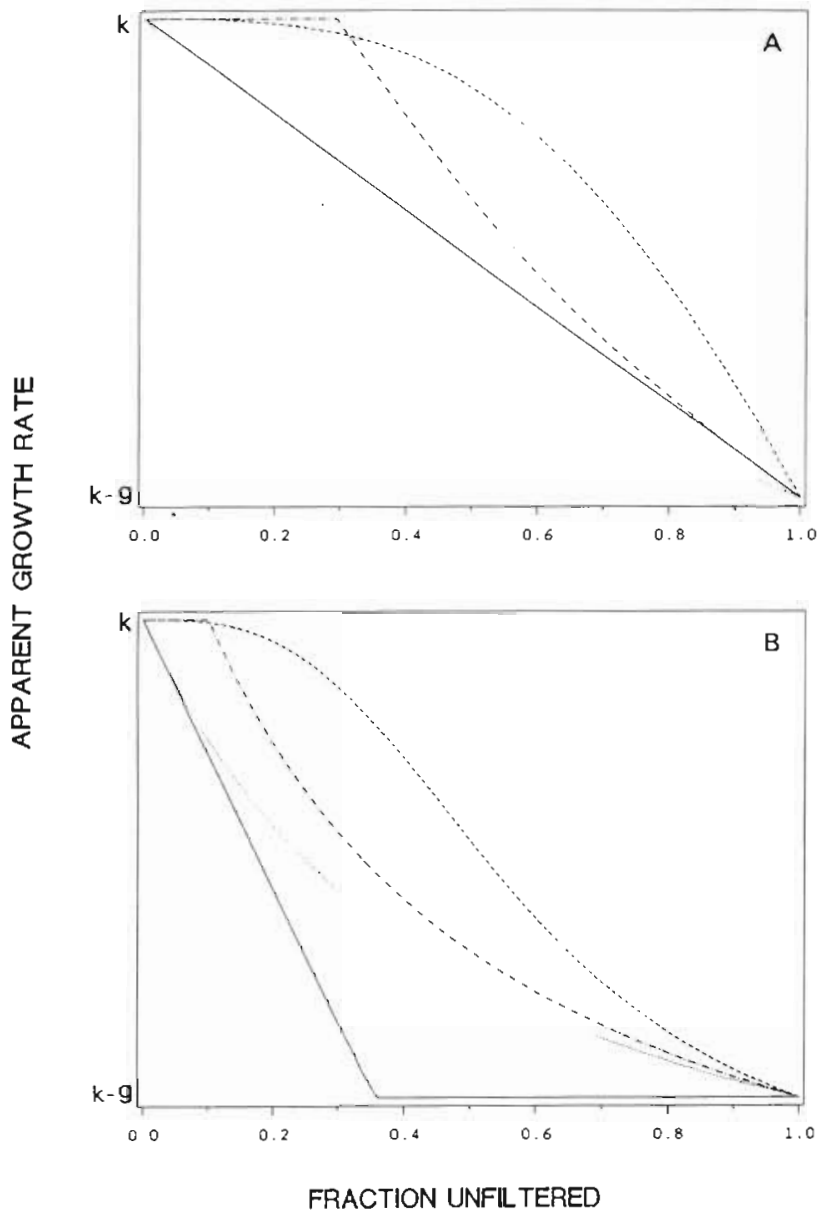

Fig. 2. Curves of apparent growth rate versus fraction unfiltered water generated using functional response curves shown in Fig. 2. (-) Type I; (.......) Type II; (-..) Type IIa; $(--)$ Type III. (A) Initial prey density $=\mathrm{P}_{1}$; (B) initial prey density $=P_{2}$

trations of $P_{1}$ in Fig. 2. All of the curves display departure from linearity, except for Type I when $P_{1}$ is below the saturation level. More importantiy though, all of the curves intersect the $y$-axis at $k$; this is because $f_{\mathrm{X}}(0)=0$, i.e. there can be no food consumption at zero food concentration.

It is clear that the behavior of the $r_{\mathrm{X}} \mathrm{vs} \mathrm{X}$ curve at low values of $\mathrm{X}$ is critical for obtaining reliable estimates of $k$. It is possible to estimate $k$ and $g$ using a 3-point modification of the 2-point method, by extrapolating the $r_{\mathrm{X}}$ vs $\mathrm{X}$ curve to $\mathrm{X}=0$ using the lowest 2 dilutions

$$
k=\frac{\mathrm{X}_{2} r_{\mathrm{X}, 1}-\mathrm{X}_{1} r_{\mathrm{X}, 2}}{\mathrm{X}_{2}-\mathrm{X}_{1}}
$$

where the subscripts 1 and 2 refer to lowest and second lowest values of $\mathrm{X}$ and their corresponding values of $r_{\mathrm{X}}$; $g$ is then estimated from Eq. (1b). It will be shown in the 'Discussion' that estimates of $g$ (but not $k$ ) obtained in this way are very sensitive to the simplifying assump- 
tions used to derive Eq. $(7 \mathrm{c})$; an unbiased alternative formula will be derived. This analysis implies that several highly diluted incubations must be performed to obtain reliable estimates of $k$ whenever nonlinear feeding kinetics are suspected. Practical aspects of performing highly diluted incubations will be addressed in the 'Discussion'.

\section{MATERIALS AND METHODS}

Study site. Experiments were conducted at the Smithsonian dock on the Rhode River, Maryland, USA, a turbid, eutrophic subestuary on the western shore of the Chesapeake Bay. Mean depth is $2 \mathrm{~m}$, and maximum depth is nearly $5 \mathrm{~m}$. Salinity varies seasonally from ca 5 to $20 \%$ at the mouth of the river, and from 0 to $17 \%$ at the head. Nutrient concentrations in the system are generally high. Phosphate concentrations typically peak in the summer at about $5 \mu \mathrm{M}$; nitrate becomes undetectable during the summer, but ammonium is always present, averaging about $4 \mu M$ (Jordan et al. unpubl.). Chlorophyll concentrations are high during the summer, averaging about $50 \mu \mathrm{g} \mathrm{l^{-1 }}$ near the dock (Jordan et al. unpubl.). Dominant phytoplankton taxa in the summer are larger (Gymnodinium nelsoni, Gyrodinium uncatenum) and small (Gyrodinium estuariale, Amphidinium sp.) dinoflagellates, and cryptomonads (Gallegos unpubl.).

Experimental procedures. Incubations were carried out in 8 l polyethylene bags containing 5 to $6 \mathrm{l}$ of whole or diluted sample. In the first experiment bags were suspended in situ at a depth of $1 \mathrm{~m}$. For all other experiments, incubations were carried out on the dock in a $116 \mathrm{l}$ Nalgene tank with flowing river water. Incubations commenced at 09:30 to 10:30 h local time and were terminated after $24 \mathrm{~h}$. Excess nutrients as $\mathrm{NO}_{3}^{-1}$ and $\mathrm{PO}_{4}^{-3}$ were added at concentrations of 44 and $1.8 \mu M$ respectively, to avoid overestimation of grazing impact due to nutrient depletion in the bags (Landry \& Hassett 1982, Burkill et al. 1987. Paranjape 1987).

In the first 2 experiments filtered water for the dilutions was prepared using Gelman AE glass fiber filters. In the second experiment I found that ca $5 \%$ of the initial chlorophyll passed this filter; Whatman GF/F filters were used to prepare filtered water in subsequent experiments; no growth of phytoplankton was detected in a control incubation of $100 \% \mathrm{GF} / \mathrm{F}$ filtered water. Filtered water was prepared a day in advance because of the large volume needed (about $30 \mathrm{I}$ ) and because of the high biomass levels: filters clogged after passing ca 300 to $400 \mathrm{ml}$. Filtered water was stored in the dark in 20 l. polyethylene carboys.

Phytoplankton growth in the incubations was estimated by changes in chlorophyll concentrations (Landry \& Hassett 1982). Particulate material was collected on Whatman GF/F filters with a small amount of $\mathrm{MgCO}_{3}$ and extracted in $90 \%$ acetone in the dark at $4{ }^{\circ} \mathrm{C}$ for $18 \mathrm{~h}$. Extracts were centrifuged and absorbances at selected wavelengths were determined spectrophotometrically; pigment concentrations were calculated by the equations of Jeffrey \& Humphrey (1975). Subsamples were preserved with Lugol's iodine (ca $1 \%$ ) at the end of the incubations for determination of dominant phytoplankton and microzooplankton taxa.

\section{RESULTS}

Four experiments were carried out between July and October 1988; a wide range of initial chlorophyll con-

Table 1. Ancillary data for dilution experiments in Rhode River, Maryland, USA

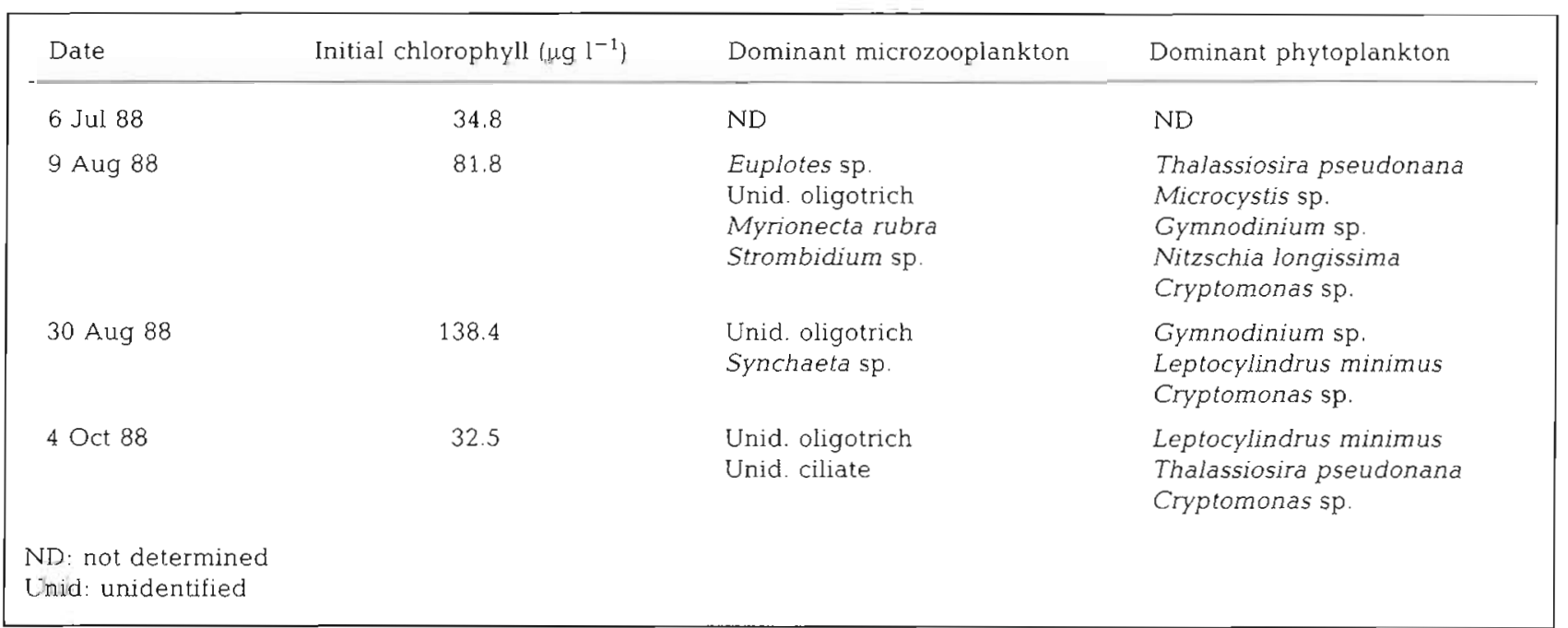


Fig. 3. Curves of apparent growth rate as a function of fraction unfiltered water for experiments in Rhode River, Maryland, USA
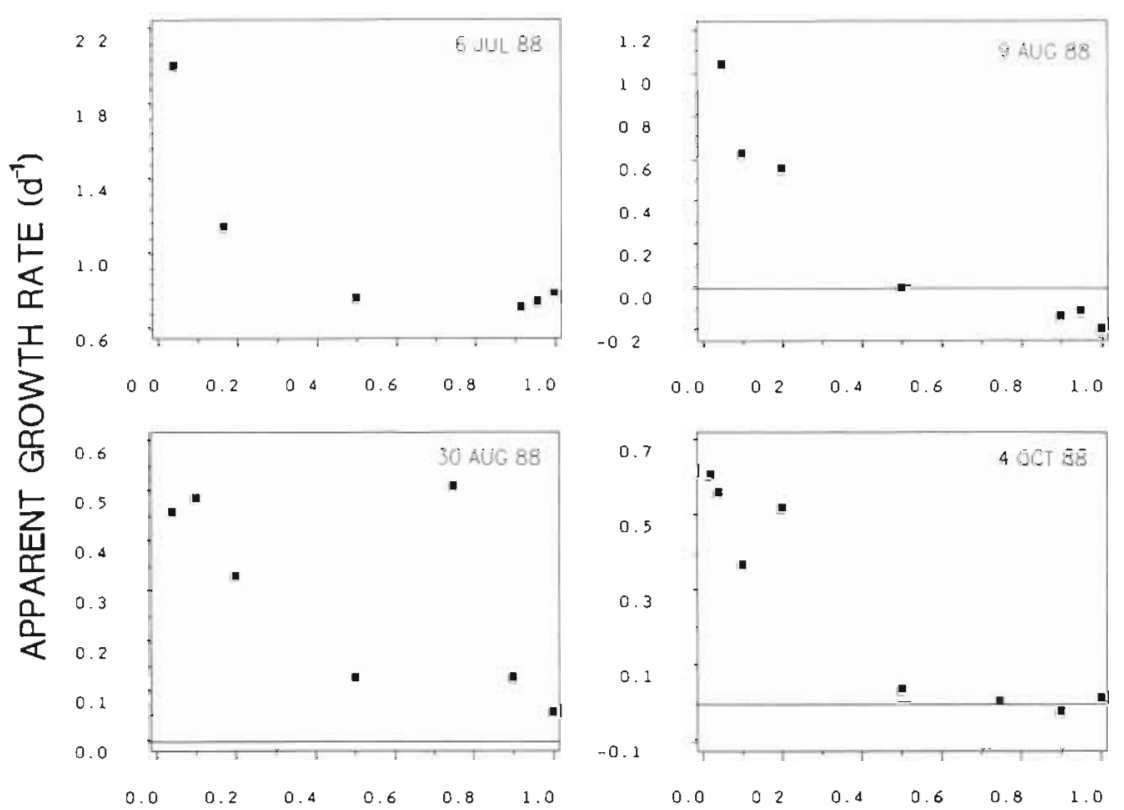

FRACTION UNFILTERED centrations was encountered, but all would be considered eutrophic (Table 1). Nonlinearity, indicative of saturated feeding responses, was evident in the plots of apparent growth rate vs fraction of unfiltered water in each of the experiments (Fig. 3); there is virtually no slope to the plots for $\mathrm{X}>0.5$. For any given experiment the number of points is too few to conclude significant departure from linearity based on a runs test (Sokal \& Rohlf 1981). Nevertheless, in nearly all cases, estimates of specific growth and grazing rates obtained by linear regression are lower than the 3-point estimates (Table 2); an exception is the experiment of 30 August for which random error seemed to be large enough to give similar estimates by regression. Estimates of $k$ and $g$ obtained using the 2-point calculation method increase systematically with decreasing $X$, with a few exceptions due presumably to random error (e.g. 30 August, $X=0.1 ; 4$ October, $X=0.2$ ). Due to the evident feeding saturation, the 2-point method with $X$ $=0.5$ gives estimates of $k$ much lower than actual measurements of $r_{\mathrm{X}}$ for $\mathrm{X}<0.1$. The 2 -point method with $X \leqq 0.05$ gives estimates of $k$ and $g$ much closer to those obtained by the 3-point estimates. This is because as $\mathrm{X} \rightarrow 0$, the slope at which the curve of $I_{\mathrm{X}}$ vs $X$ is extrapolated to zero becomes unimportant; i.e. in these experiments, $0.05 \sim 0$. Because of the assumptions used to derive the 3 -point method of calculating $g$. the values given in Table 2 must be regarded as preliminary. Revised estimates based on a time-dependent model of grazing dynamics will be given in the 'Discussion'.
The normalized functional response curves for each experiment were calculated using the 3-point estimates of $k$ and $g$ given in Table 3 . These are shown on a single plot in Fig. 4. Again, the saturation of feeding responses above $\mathrm{X}=0.5$ is apparent. Pooling all results on a common curve, the normalized functional response shows significant quadratic (i.e. nonlinear) dependence on $X$, and therefore departure from linearity $(F=51.8, p<0.001)$. Half-saturation prey densities appear to be in the range 0.1 to $0.2 P_{1}$. This range is considerably smaller than the range of initial chlorophyll levels (Table 1), which vary by a factor of 4 .

\section{DISCUSSION}

Nonlinearity in the relationship of apparent growth rate to fraction of unfiltered water in the dilution incubations was apparent in samples from the Rhode River (Fig. 3). Are the apparent nonlinear kinetics an artifact of the simplifying assumptions used to derive Eq. (7)? That is, can increase in microzooplankton density during the incubations give the appearance of nonlinear feeding response, even if clearance rates remain constant? Does continuous adjustment of clearance rates to changing phytoplankton density distort the detected functional response? Moreover, how sensitive are the derived coefficients, $k$ and $g$, to violations of these assumptions? To address these questions it is necessary to consider a time-dependent model of microbial com- 
Table 2 . Specific growth and grazing coefficients estimated by 3 methods for dilution experiments in the Rhode River. Standard errors of regression coefficients are given in parentheses

\begin{tabular}{|c|c|c|c|}
\hline \multirow[t]{2}{*}{ Date } & \multirow{2}{*}{$\begin{array}{l}\text { Calculation } \\
\text { method }\end{array}$} & \multicolumn{2}{|c|}{ Parameter estimates } \\
\hline & & $\begin{array}{c}k \\
\left(d^{-1}\right)\end{array}$ & $\left(d^{-1}\right)$ \\
\hline \multirow[t]{5}{*}{$6 \mathrm{Jul} 88$} & Linear regression & $1.61(0.33)$ & $0.96(0.35)$ \\
\hline & 2-Point, $X=0.50$ & 0.78 & 0.02 \\
\hline & $x=0.17$ & 1.23 & 0.47 \\
\hline & $X=0.04$ & 2.06 & 1.30 \\
\hline & 3-Point & 2.30 & 1.54 \\
\hline \multirow[t]{6}{*}{9 Aug 88} & Linear regression & $0.82(0.19)$ & $1.07(0.18)$ \\
\hline & 2-Point, $X=0.50$ & 0.14 & 0.28 \\
\hline & $\mathrm{x}=0.20$ & 0.73 & 0.87 \\
\hline & $X=0.10$ & 0.71 & 0.85 \\
\hline & $X=0.05$ & 1.11 & 1.25 \\
\hline & 3-Point & 1.46 & 1.60 \\
\hline \multirow[t]{6}{*}{30 Aug 88} & Linear regression & $0.46^{\mathrm{a}}(0.08)$ & $0.41^{\mathrm{a}}(0.08)$ \\
\hline & 2-Point, $X=0.50$ & 0.20 & 0.14 \\
\hline & $X=0.20$ & 0.40 & 0.34 \\
\hline & $X=0.10$ & 0.54 & 0.48 \\
\hline & $x=0.04$ & 0.48 & 0.42 \\
\hline & 3-Point & 0.48 & 0.41 \\
\hline \multirow[t]{7}{*}{4 Oct 88} & Linear regression & $0.55(0.12)$ & $0.64(0.11)$ \\
\hline & 2-Point, $X=0.50$ & 0.08 & 0.07 \\
\hline & $X=0.20$ & 0.69 & 0.65 \\
\hline & $X=0.10$ & 0.41 & 0.41 \\
\hline & $X=0.04$ & 0.59 & 0.58 \\
\hline & $X=0.02$ & 0.62 & 0.62 \\
\hline & 3-Point & 0.66 & 0.66 \\
\hline
\end{tabular}

munity dynamics in which microzooplankton density may change and ingestion is a continuous function of phytoplankton density. Assuming that microzooplankton growth is exponential and that growth is coupled to ingestion, we may write

$$
\begin{aligned}
& \frac{\mathrm{dP}}{\mathrm{d} t}=\mathrm{P}\left[k-\mathrm{Z} \cdot \frac{f(\mathrm{P})}{\mathrm{P}}\right] \\
& \frac{\mathrm{dZ}}{\mathrm{d} t}=\mathrm{Z}[\psi f(\mathrm{P})-m]
\end{aligned}
$$

where $\mathrm{Z}$ and $\mathrm{P}$ are now expressed in consistent mass units (e.g. $\left.\mu \mathrm{g} \mathrm{C} \mathrm{l}^{-1}\right)_{i} \psi$ (dimensionless) = growth efficiency for the microzooplankton; $f(P)=$ the functional response for specific ingestion rate $\left[\mu \mathrm{g} \mathrm{C}(\mu \mathrm{g} C)^{-1} \mathrm{~d}^{-1}\right]$; and $m\left(d^{-1}\right)=$ mortality rate of the microzooplankton. For simplicity, consider a Type I functional response

$$
\begin{array}{rlrl}
f(\mathrm{P}) & =\mathrm{C}_{\mathrm{T}} \mathrm{P} & \left\{\mathrm{P}<\mathrm{P}_{\mathrm{s}}\right\} \\
& =\mathrm{C}_{\mathrm{s}} \mathrm{P}_{\mathrm{s}} \quad\left\{\mathrm{P} \geqq \mathrm{P}_{\mathrm{s}}\right\}
\end{array}
$$

where $C_{r}\left[1(m g C)^{-1} d^{-1}\right]$ is a carbon-specific maximum clearance rate.

The first question (i.e. whether apparent nonlinear kinetics can occur as an artifact of increasing microzooplankton density with otherwise linear feeding kinetics) can be addressed by ensuring that $P<P_{s}$. In this case, $P$ and $Z$ occur multiplicatively in both equations and no analytical solution exists. A computer program was written to solve Eqs. (9) numerically using a 4 thorder Runge-Kutta integration. Values of $P$ and $Z$ at the end of $1 \mathrm{~d}$ were simulated and apparent growth rates of the phytoplankton were calculated by the usual formula (Eq. 2). Correct coding was verified by setting $\psi=$ $m=0$ (i.e. no microzooplankton dynamics) which gave linear decrease in apparent growth rate with $X$ and had slope and intercept as predicted by Eq. (2).

Coefficients for the time-dependent simulation were modeled after the experiment of 6 July 1988 (Fig. 3; Table 1). Using a $C$ : chl ratio of 30 for turbid water

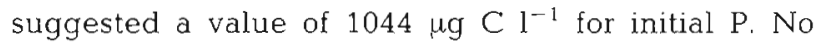
information was available for choosing coefficients governing microzooplankton dynamics in these experiments; it seemed that allowing microzooplankton dynamics to match those estimated for the phytoplank-

\begin{tabular}{|c|c|c|c|c|c|}
\hline Date & $\underset{\left(d^{-1}\right)}{g}$ & $\begin{array}{l}\text { Potential chlorophyll } \\
\text { production }\left(\mu \mathrm{g} \mathrm{I} \mathrm{I}^{-1}\right)\end{array}$ & $\begin{array}{l}\text { Actual chlorophyll } \\
\text { production }\left(\mu \mathrm{g} \mathrm{l}^{-1}\right)\end{array}$ & $\begin{array}{l}\text { Initial stock } \\
\text { grazed }(\%)\end{array}$ & $\begin{array}{c}\text { Potential production } \\
\text { grazed }(\%)\end{array}$ \\
\hline \multicolumn{6}{|c|}{$k_{\mathrm{z}}=0 \mathrm{~d}^{-1}$} \\
\hline 6 Jul 88 & 2.01 & 312.3 & 39.6 & 78.6 & 87.3 \\
\hline 9 Aug 88 & 1.52 & 270.4 & -10.7 & 79.8 & 104.0 \\
\hline 30 Aug 88 & 0.42 & 86.4 & 10.2 & 33.9 & 88.2 \\
\hline $4 \operatorname{Oct} 88$ & 0.66 & 30.4 & 0.1 & 48.1 & 99.6 \\
\hline \multicolumn{6}{|c|}{$k_{\mathrm{z}}=1.5 \mathrm{~d}^{-1}$} \\
\hline 6 Jul 88 & 1.14 & 312.3 & 76.2 & 68.0 & 75.6 \\
\hline 9 Aug 88 & 0.78 & 270.4 & 79.7 & 54.2 & 70.5 \\
\hline 30 Aug 88 & 0.19 & 85.3 & 46.6 & 17.3 & 45.4 \\
\hline 4 Oct 88 & 0.31 & 30.4 & 13.6 & 26.7 & 55.3 \\
\hline
\end{tabular}
ton $\left[\psi \mathrm{C}_{\mathrm{r}} \mathrm{P}_{1}(0)=k=2.3, m=g=\mathrm{C}_{\mathrm{r}} \mathrm{Z}=1.54\right]$ would be a

Table 3. Summary of potential impact of microzooplankton grazers on phytoplankton chlorophyll in experiments on Rhode River. Estimates of grazing coefficient, $g$, and grazing impact are given for 2 different estimates of microzooplankton net growth rate $k_{z}$ 
Fig. 4. Normalized functional response curves extracted from measurements of $k$ and $g$ using data in Fig. 3. (1) 6 Jul 1988; () 9 Aug 1988; (:) 30 Aug 1988; (†) 4 Oct 1988. Arrows on abscissa bracket range of relative initial chlorophyll $\left(\mathrm{P} / \mathrm{P}_{0}\right)$ required to half-saturate microzooplankton ingestion

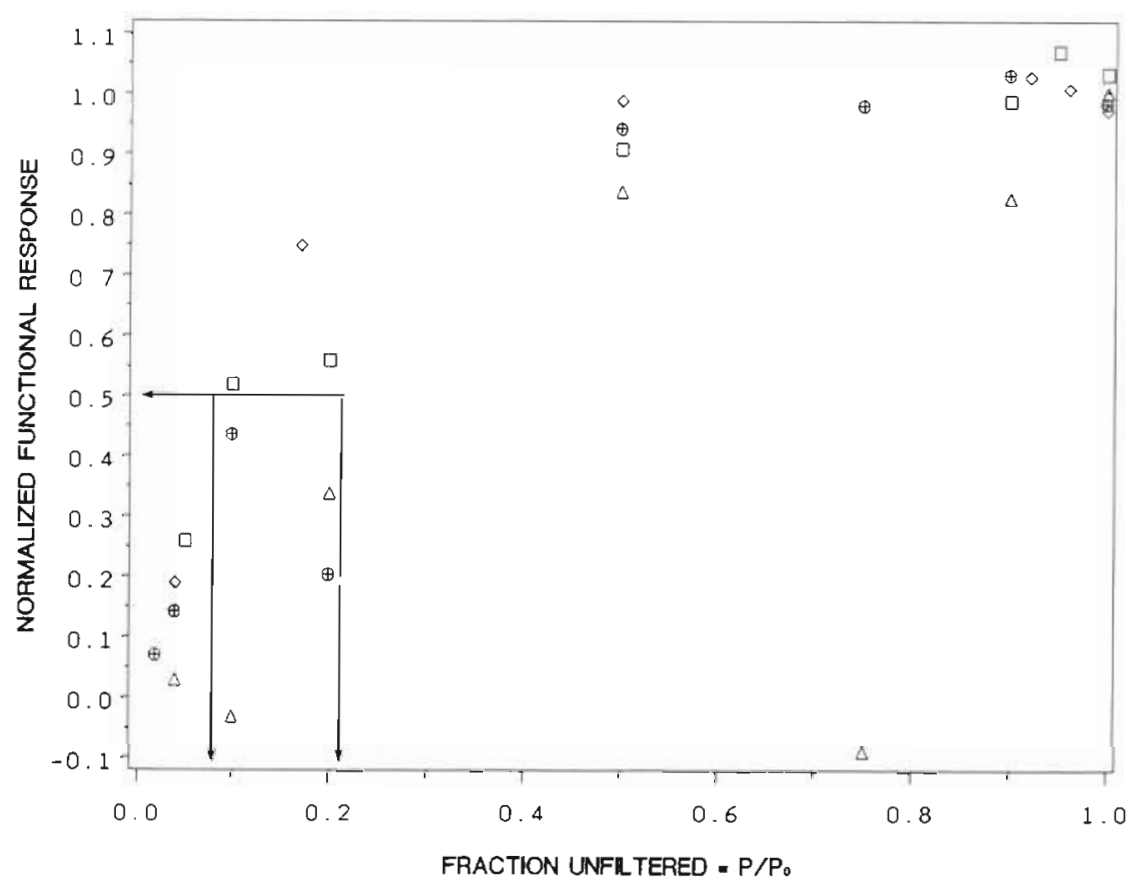

rigorous test of the model. The coefficients were still under-determined, so I arbitrarily set $\psi=0.2$, which

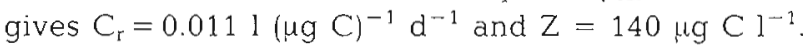
(The somewhat low values for $\psi$ and $C_{r}$ are necessary to give reasonable values of microzooplankton growth rates at such high $\mathrm{P}$ when assuming linear kinetics.) It is possible that the initial mortality rate of the microzooplankton is altered by the dilution protocol; 3 possibilities were investigated. If the major predators of the grazers are themselves members of the microzooplankton, then dilution would reduce encounter rates and $m$ would be reduced in proportion to $X$. If predators on the microzooplankton are unsampled or eliminated by screening then, for the short term, $m$ could be reduced to 0 in the limit. Alternatively, if mortality is primarily a consequence of the age structure of the microzooplankton initially present then $m$ might remain unaltered. (Initial loss of microzooplankton due
Fig. 5. (A) Effects of microzooplankton density increase on apparent growth rates of phytoplankton during dilution experiments simulated using Eqs. (9). Linear feeding response of microzooplankton was assumed. Solid line gives predicted response if no microzooplankton increase occurred. (-) Microzooplankton mortality, $m \propto X_{;}(\bullet) m=0 ;(\mathbf{A})$ $m=1.6 \mathrm{~d}^{-1}$ (B) Normalized functional responses (NFR) extracted from data in (A). Solid line was used in the simulation. (C) As in (A) but with nonlinear feeding kinetics simulated. (D) As in (B), but estimated from data in (C)
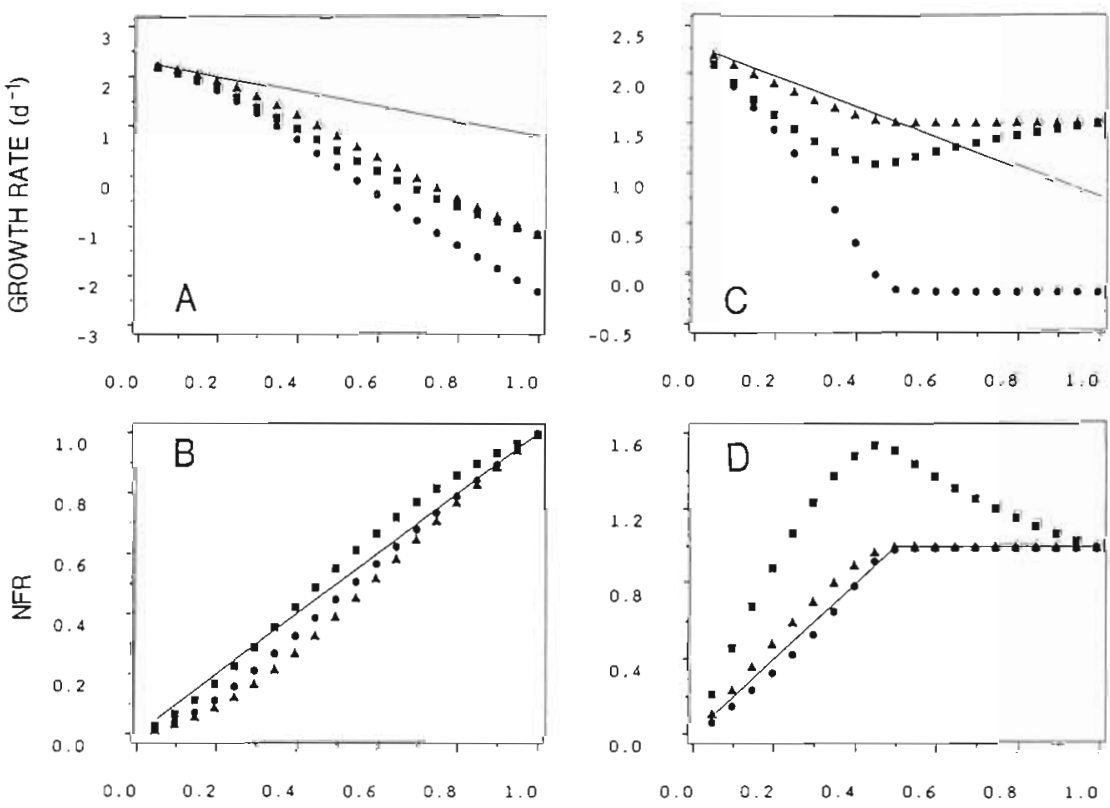

FRACTION UNFILTERED SEAWATER 
to handling would appear as reduction in initial biomass, which was not systematicaily investigated.)

Simulation of Eqs. (9) with coefficients and initial conditions as given above gave apparent growth rates of the phytoplankton that were substantially reduced over those predicted using constant grazer density for all assumptions about alteration of grazer mortality (Fig. 5A). Only at very high dilutions $(X \leqq 0.10)$ do the points conform to the linear prediction. Maximum net growth rates of microzooplankton in the simulations ranged from 1.08 to $1.78 \mathrm{~d}^{-1}$ depending on the assumption for mortality. Growth rates, $k$, calculated by Eq. (8) agreed with simulated values to within $2 \%$, but growth rates calculated by linear regression of apparent growth rate against $\mathrm{X}$ are overestimated (see below). Some nonlinearity in the plots of apparent growth rate against fraction of unfiltered seawater was introduced by growth of microzooplankton, but the derived normalized functional responses (Fig. 5B) do not suggest saturated feeding responses (cf. Fig. 4).

Nonlinear feeding behavior was simulated by setting $\mathrm{P}_{\mathrm{s}}=522 \mu \mathrm{g} \mathrm{C} \mathrm{l}^{-1}$ [i.e. $\mathrm{P}_{1}(0) / 2$ ]. To maintain initial grazing pressure the same as in the first simulation it was necessary to double initial microzooplankton density. As in the first simulation, apparent growth rates at very high dilutions accurately predicted $k$ using Eq. (8) (Fig. 5C). Estimates of total grazing impact at low dilutions differ in both sign and magnitude from that based on the assumption of linear feeding response and no microzooplankton growth (see discussion of bias below). Maximum net growth rates of microzooplankton in these simulations ranged from -0.39 to $1.15 \mathrm{~d}^{-1}$. The normalized functional responses estimated from the simulated data showed only slight distortions when microzooplankton mortality was assumed to be independent of dilution level (Fig. 5D), but simulation with microzooplankton mortality proportional to $X$ gave the appearance of a functional response with inhibition of feeding at high relative food density. This is because with mortality assumed to be proportional to $\mathrm{X}$, net microzooplankton growth, and hence grazing impact, is maximal at intermediate dilutions where food limitation and mortality rates are simultaneously relaxed. This type of response has not been observed in experiments conducted to date and hence the remaining discussion will be restricted to models assuming grazer mortality independent of dilution fraction.

When feeding kinetics are linear the bias in calculated rates may be largely eliminated by regressing apparent growth rate against relative mean predator density, instead of against the fraction of unfiltered seawater (Landry et al. 1984). This transformation expands the $X$ axis when there is a net increase in microzooplankton, appropriately reducing the calcu- lated slope and intercept. With saturated feeding kinetics expansion of the $X$ axis does not linearize the curve, because apparent growth rate becomes independent of $X$. Furthermore, there is an inherent bias in the 3-point method of calculating $g$ as the difference between estimated $k$ and $r_{n}$ in the undiluted incubation. The bias, which may be corrected, is a result of the continuous reduction of clearance rates when food concentrations are above saturation levels and is present even when there is no net microzooplankton growth. In all dilutions in which $\mathrm{P}>\mathrm{P}_{\mathrm{s}}$, microzooplankton growth in Eq. (9b) becomes independent of P. Thus we may solve Eq. (9b) for $\mathrm{Z}(t)$

$$
Z(t)=Z(0) \exp \left(k_{z} t\right)
$$

where $k_{z}=\psi C_{\tau} P_{s}-m=$ net microzooplankton growth rate; and $m$ may or may not be altered by dilution, but is assumed to be independent of $X$. Substituting Eq. (10) into (9a) we may solve for $P(t)$

$$
\frac{\mathrm{P}(t)}{\mathrm{P}(0)}=\exp (k t)-g \frac{\left[\exp \left(k_{z} t\right)-\exp (k t)\right]}{k_{z}-k}
$$

where $g=\mathrm{Z}(0) \mathrm{C}_{\mathrm{r}} \mathrm{P}_{\mathrm{s}} / \mathrm{P}(0)$ is the grazing coefficient for the initial conditions. (The solution remains defined when $k_{\mathrm{z}}=k$ because the fraction multiplying $g$ on the right hand side of Eq. [11] approaches $e^{k t}$ as $k_{z} \rightarrow k$.) Given that $k$ can be estimated accurately using highly diluted incubations, we can estimate $g$ for saturated

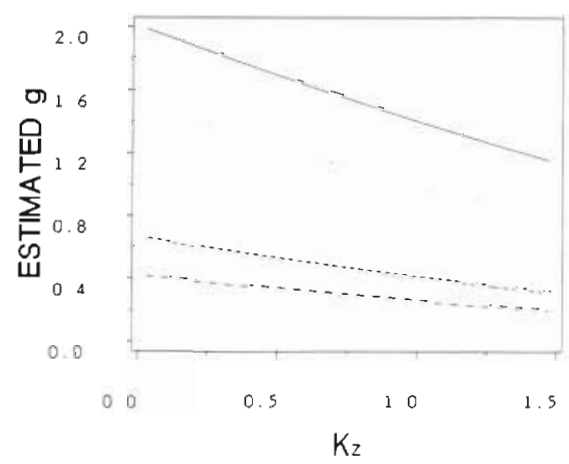

Fig. 6. Variation of estimated grazing coefficient $g\left(d^{-1}\right)$ with microzooplankton net growth rate, $k_{z}$. (—) 6 Jul 1988; (…...) 9 Aug $1988 ;(---) 30$ Aug 1988; (--.-) 4 Oct 1988

feeding responses using Eq. (11) whenever estimates of $k_{z}$ are available. Lacking explicit knowledge of microzooplankton growth rates, we can only bracket the estimates of $g$ over a range of possible $k_{z}$. Estimates of $k$ and measured $\mathrm{P}_{1}(t) / \mathrm{P}_{1}(0)$ from the experiments on the Rhode River were used with Eq. (11) to revise estimates of $g$ for $k_{z}$ varying from 0 to 1.5 ( $\simeq 2$ doublings) $\mathrm{d}^{-1}$ (Fig. 6). Absolute estimates of $g$ were most sensitive to microzooplankton growth at the highest $k$, but the proportionate reduction in $g$ as $k_{z}$ varies from 0 to 1.5 is 
slightly higher for experiments having lower estimated $k$ 's. Overall the estimated $g$ 's for $k_{z}=1.5$ range from 48 to $57 \%$ of the estimates at $k_{z}=0$.

Using the 3-point estimates of $k$ and bracketed estimates of $g$, I calculated the grazing impact of microzooplankton in this system for $k_{z}=0$ and $k_{z}=$ $1.5 \mathrm{~d}^{-1}$ (Table 3). In the absence of net increase of the microzooplankton, grazing is capable of removing from 34 to $87 \%$ of initial standing stock, and 90 to $102 \%$ of potential daily production, which would suggest close coupling between growth and grazing in this system. If net microzooplankton increase is as high as $1.5 \mathrm{~d}^{-1}$, the calculated impact would be reduced to 17 to $68 \%$ of initial standing stock, and 45 to $76 \%$ of potential daily production. With either set of parameter estimates, the calculated percentages are well within the range observed by others (Landry \& Hassett 1982, Paranjape 1987, Gifford 1988). Clearly more information on net rates of microzooplankton growth are required to properly determine the impact of microzooplankton grazing in the system.

The magnitude of specific growth and grazing coefficients determined here slightly extends the range of reported values determined by the dilution technique (Table 4). The growth coefficients are high, but the highest $\left(2.3 \mathrm{~d}^{-1}=3.3\right.$ doublings $\left.\mathrm{d}^{-1}\right)$ is within Eppley's (1972) envelope of phytoplankton growth rates for the ambient temperature

Accepting that the normalized functional response can be estimated with relatively little distortion (Fig. 5B, D), the curves obtained in these experiments indicate that the chlorophyll levels were always at saturation for the grazing communities present (Fig. 4). and that saturation was maintained to at least the $50 \%$ dilution. Below that level the normalized ingestion rates decline, but it is not possible with the present data to distinguish whether the points follow Type I, II, or IIa curves. For convenience, I will refer to half-saturation dilution fractions, since the normalized functional response at half-saturation [i.e. $\mathrm{X}$ such that $f\left(\mathrm{XP}_{1}\right) / f\left(\mathrm{P}_{1}\right)$ $=0.5]$ is better resolved by the data than is a threshold saturation level (Fig. 4).

Saturated feeding responses may not be unexpected for systems as eutrophic as the Rhode River More intriguing is the observation that the half-saturation dilution fraction varied over a relatively small range $(\sim 0.1$ to 0.2$)$, in spite of the large range of initial chlorophyll levels (Fig. 4; Table 2). Thus, half-saturation food levels in terms of chlorophyll a would necessarily be highly correlated with initial chlorophyll. Several mechanisms might account for this observation. If growth rates of microzooplankton do indeed approach those of their phytoplankton food source (e.g. Verity 1985), then the microzooplankton community might closely track variations in food supply. Community structure could respond relatively rapidly to phytoplankton blooms, especially in the summer when temperatures do not limit growth rates (Pomeroy \& Deibel 1986). It is possible that phytoplankton blooms support an assemblage of microzooplankton grazers with higher energy demands, and consequently higher halfsaturation food levels. Short-term behavioral responses by the microzooplankton grazers could also explain the results. The half-saturation chlorophyll concentration is an indicator of the range of food levels over which maximal clearance rates are maintained. The observation that food levels are saturating implies that clearance rates in these experiments were less than maximal at ambient food levels, and that clearance rates increased proportionally with dilution until maximal rates were reached at $c a X=0.5$ to 0.3 . Explanation in terms of short-term behavioral responses would imply that the microzooplankton are acclimated to the various ambient food levels, and that increases in clearance rates takes place in response to perceived reductions in encounter rates. Busky \& Stoecker (1988) found transitory responses in tactic and kinetic behavior of the tintinnid Favella sp. to changes in food density; accli-

Table 4. Comparison of specific growth $(k)$ and grazing $(g)$ coefficients determined by dilution technique in different regions. Range of grazing coefficients for Rhode River are given for 2 assumed values of net growth rate of microzooplankton, $k_{z}$

\begin{tabular}{|c|c|c|c|}
\hline Location & $\begin{array}{c}\text { Range } k \\
\left(d^{-1}\right)\end{array}$ & $\begin{array}{c}\text { Range } g \\
\left(\mathrm{~d}^{-1}\right)\end{array}$ & Source \\
\hline Coastal Washington, USA & $0.45-0.62$ & $0.07-0.28$ & Landry \& Hassett (1982) \\
\hline Kaneohe Bay, Hawaii & $1.40-2.00$ & $0.10-0.40$ & Landry et al. (1984) \\
\hline Celtic Sea, British Isles & $0.16-0.35^{\mathrm{a}}$ & $0.19-1.04^{\mathrm{a}}$ & Burkill et al. (1987) \\
\hline Jones Sound, Canadian arctic & $0.10-0.34$ & $0.00-0.17$ & Paranjape (1987) \\
\hline Halifax Harbor, NS, Canada & $0.24-1.68$ & $0.02-0.72$ & Cifford (1988) \\
\hline \multirow[t]{2}{*}{ Rhode River, Maryland, USA } & $0.48-2.30$ & $0.42-2.01$ & This study, $k_{z}=0$ \\
\hline & & $0.19-1.14$ & This study, $k_{z}=1.5$ \\
\hline
\end{tabular}


mation to new concentrations took place over 30 to 60 min. Present data do not allow differentiation between these 2 mechanisms, which are not mutually exclusive.

It remains to be determined how general nonlinear feeding kinetics are in this and other marine systems. Of published accounts, only Gifford (1988) used dilutions as high as $95 \%$, which would be capable of resolving nonlinearities. She encountered 2 instances of apparent feeding thresholds, with insignificant consequences for estimates of growth and grazing coefficients. The maximum chlorophyll concentration in Halifax Harbor of $2.9 \mu \mathrm{g} 1^{-1}$ was evidently below saturation. This would imply that most oceanic environments should be below saturation levels most of the time, but feeding thresholds could be encountered. Alternatively, if the assemblage of microzooplankton grazers present in oceanic environments are acclimated to lower food levels and have clearance rates less than maximal at ambient chlorophyll concentrations, then nonlinear feeding kinetics could become evident even there. Experiments employing highly diluted incubations ( $\geq 95 \%$ ) are needed in a wider range of environments.

Highly diluted incubations should not prove excessively difficult to perform in environments more oligotrophic than the one examined here. The 2 principal considerations are the time and labor required to prepare the filtered water, and having enough autotrophic biomass to obtain an estimate of apparent growth rate after incubation. Preparation of filtered water is generally easier in more oligotrophic systems. For biomass estimates I determined chlorophyll spectrophotometrically. Fluorometric methods are considerably more sensitive; Gifford (1988) obtained estimates of apparent growth rates in $95 \%$ dilutions using $250 \mathrm{ml}$ containers with initial chlorophylls as low as $0.3 \mu \mathrm{g} \mathrm{l}^{-1}$ In open ocean waters, the autotrophic organisms of interest are procaryotic and eucaryotic picoplankton, which are counted by filtration onto membrane filters. Low biomass should pose no problems in these waters with proper choice of final filtration volume (e.g. Landry et al. 1984); precautions to account for any organisms passing the filters ( $\mathrm{Li} 1986, \mathrm{Li} \&$ Dickie 1986) must be observed.

Nutrient limitation, the other principal concern with the dilution technique, has not been addressed here. In these experiments I added excess nutrients, as did Landry \& Hassett (1982) and Paranjape (1987). The major concerns with nutrient additions are that the growth coefficients may be artificially elevated and not representative of true in situ growth rates (Landry \& Hassett 1982), and that nutrient addition may result in substantial loss of oligotrich ciliates (Gifford 1988) The close coupling of grazing and growth observed in these experiments argue that the overall grazing was not greatly impaired by nutrient addition, although certain components of the microzooplankton community could have been lost. The continual presence of $\mathrm{NH}_{4}^{+}$in this system suggests that nutrients would generally be available for growth, although containment and dilution of the grazing community could result in depletion during the incubations. If this were the case, then nutrient additions would be appropriate. Comparisons of nutrient additions with incubations in diffusion chambers (e.g. Landry \& Hassett 1982) are needed to resolve the question for this system.

\section{CONCLUSIONS}

The dilution technique for estimating microzooplankton grazing is a simple manipulation of a complex food web. Our ability to interpret results from such experiments will continue to evolve as our understanding of microbial interactions improves. I have shown that saturated feeding responses pose no special problems for the dilution technique, provided (1) sufficiently dilute incubations are performed in order to resolve phytoplankton growth rate, and (2) estimates of microzooplankton net growth rate are made. Without knowledge of microzooplankton growth rate we can only bracket estimates of grazing impact, which in these experiments gave a lower limit of ca $50 \%$ of the no-growth estimate. In spite of rather strict assumptions, the normalized functional response curve, which contains information about the feeding behavior of the microzooplankton community, can be extracted from the measurements. Presumably, the normalized functional response could be determined for grazing on individual components of the microbial community, including bacteria, if more incisive (e.g. HPLC, flow cytometry, microscopic counts) estimates of population numbers were used. Further, the normalized functional response curve should be a point of interface between community level methods such as the dilution technique, which determine grazing by its impact on growth of the prey population, and particle tracer techniques (e.g. McManus \& Fuhrman 1986, Sherr et al. 1987 b, Rublee \& Gallegos 1989) which are capabie of determining functional response curves directly on individual grazers. Simultaneous application of these techniques could provide an additional internal check on rate estimates determined by different methods.

Acknowledgements. I thank P. Rublee for encouragement and valuable discussions of this work. fam grateful to $\mathrm{T}$. Jordan and K. Sellner for helpful comments on the manuscript, and to S. Hedrick for assistance with the experiments. Constructive comments by anonymous reviewers improved an earlier version of the paper 


\section{LITERATURE CITED}

Burkill, P. H., Mantoura, R. F. C., Llewellyn, C. A., Owens, N. J. P. (1987). Microzooplankton grazing and selectivity of phytoplankton in coastal waters. Mar Biol. 93: 581-590

Busky, E. J., Stoecker, D. K. (1988). Locomotory patterns of the planktonic ciliate Favella sp: adaptations for remaining within food patches. Bull. mar. Sci. 43: 783-796

Ducklow, H. H., Hill, S. M. (1985). The growth of heterotrophic bacteria in the surface waters of warm core rings. Limnol. Oceanogr. 30: 239-259

Ducklow, H. H., Purdie, D. A., Williams, P. J. LeB., Davies, J M. (1986). Bacterioplankton: a sink for carbon in a coastal marine plankton community. Science 232: 865-867

Eppley, R. W. (1972). Temperature and phytoplankton growth in the sea. Fish. Bull. U.S. 70: 1063-1085

Gifford, D. J. (1988). Impact of grazing by microzooplankton in the Northwest Arm of Halifax Harbour, Nova Scotia. Mar. Ecol. Prog. Ser. 47: 249-258

Harrison, W. G. (1980). Nutrient regeneration and primary production in the sea. In: Falkowski, P. G. (ed.) Primary productivity in the sea. Plenum Press, New York, p. 433-460

Holling, C. S. (1959). Some characteristics of simple types of predation and parasitism. Can. Entomol. 91 385-398

Jeffrey, S. W., Humphrey, G. F. (1975). New spectrophotometric equations for determining chlorophyll $a, b, c_{1}$, and $c_{2}$ in higher plants, algae and natural phytoplankton. Biochem Physiol. Pflanz. 167: 191-194

Landry, M. R., Haas, L. W., Fagerness, V. L. (1984). Dynamics of microbial plankton communities: experiments in Kaneohe Bay, Hawaii. Mar Ecol. Prog. Ser. 16: 127-133

Landry, M. R., Hassett, R. P. (1982). Estimating the grazing impact of marine microzooplankton. Mar. Biol. 67 $283-288$

Li, W. K. W. (1986). Experimental approaches to field measurements: methods and interpretation. Can. Bull. Fish Aquat. Sci. 214: 251-286

Li, W. K. W., Dickie, P. M. (1986). Growth of bacteria in seawater filtered through $0.2 \mu \mathrm{m}$ Nuclepore membranes:

This article was presented by Drs E. and B. Sherr, Savannah, Georgia, USA implications for dilution experiments. Mar. Ecol. Prog. Ser. 26: $245-252$

McManus, G. B., Fuhrman, J. A. (1986). Bacterivory in seawater studies with the use of inert fluorescent particles. Limnol. Oceanogr 31 420-426

McManus, G. B., Fuhrman, J. A (1988). Control of marine bacterioplankton populations: measurement and significance of grazing. Hydrobiol. 159: 51-62

Paranjape, M. A. (1987). Grazing by microzooplankton in the eastern Canadian arctic in summer 1983. Mar. Ecol. Prog Ser. 40: 239-246

Pomeroy, L. R., Deibel, D. (1986). Temperature regulation of bacterial activity during the spring bloom in Newfoundland coastal waters. Science 233: 359-361

Real, L. A. (1977). The kinetics of functional response. Am Nat. 111: 289-300

Rublee, P. A., Gallegos, C. L. (1989). Use of fluorescently labeled algae (FLA) to estimate microzooplankton grazing. Mar. Ecol. Prog. Ser. 51: 221-227

Sherr, B. F., Sherr, E. B., Albright, L. J. (1987a). Bacteria: link or sink? Science 235: 88

Sherr, B. F., Sherr, E. B., Fallon, R. D. (1987b). Use of monodispersed fluorescently labeled bacteria to estimate in situ protozoan bacterivory. Appl. environ. Microbiol. 53: 958-965

Sokal, R. R., Rohlf, F. J. (1981). Biometry, 2nd edn. W. H. Freeman and Co., San Francisco

Steele, J. H. (1974). The structure of marine ecosystems. Harvard Univ. Press, Cambridge

Tremaine, S. C., Mills, A. L. (1987). Tests of the critical assumptions of the dilution method for estimating bacterivory by microeucaryotes. Appl. environ. Microbiol. 53: 2914-2921

Verity, P. G. (1985). Grazing, respiration, excretion and growth rates of tintinnids. Limnol. Oceanogr. 30: $1268-1282$

Verity, P. G. (1986). Grazing of phototrophic nannoplankton by microzooplankton in Narragansett Bay. Mar. Ecol. Prog. Ser. 29: 105-115

Manuscript first received: December 15, 1988

Revised version accepted: May 8, 1989 